\title{
Integrating language and content in the language classroom: Are transfer of knowledge and of language ensured?
}

\section{Dieter Wolff}

\section{(2) OpenEdition}

\section{Journals}

Electronic version

URL: http://journals.openedition.org/asp/1154

DOI: $10.4000 /$ asp. 1154

ISBN: 978-2-8218-0394-7

ISSN: 2108-6354

\section{Publisher}

Groupe d'étude et de recherche en anglais de spécialité

\section{Printed version}

Date of publication: 1 November 2003

Number of pages: $35-46$

ISSN: 1246-8185

Electronic reference

Dieter Wolff, « Integrating language and content in the language classroom: Are transfer of knowledge and of language ensured? », ASp [Online], 41-42 | 2003, Online since 24 April 2010, connection on 10 December 2020. URL : http://journals.openedition.org/asp/1154; DOI : https://doi.org/10.4000/asp. 1154

This text was automatically generated on 10 December 2020 .

Tous droits réservés 


\title{
Integrating language and content in the language classroom: Are transfer of knowledge and of language ensured?
}

\author{
Dieter Wolff
}

\section{Introduction}

1 There can be no doubt that in recent years language learning and teaching has become a much debated educational issue all over Europe. Since, in 1995, the European Commission in their famous White Book on Education declared that all European citizens should be made competent in at least three European languages (including their mother tongue), educationalists, teachers and administrators have been looking for appropriate ways and means to reach this highly ambitious goal. One of the most interesting proposals made is called "teaching content through a foreign language" or "content and language integrated learning" (CLIL). This language teaching and learning concept which is related to similar concepts in secondary education (for example the 'European schools' model) turns out to be very efficient with respect to the language competence attained by the students; this is at least the outcome of a small number of research projects which are confirmed by what language teachers and school authorities tell us.

The approach is based on the well-known assumption that foreign languages are best learnt by focussing in the classroom not so much on language - its form and structure but on the content through which language is transmitted. Compared to other contentbased approaches the specific novelty of this approach is that classroom content is not so much taken from everyday life or general content of the target language culture but that it is rather drawn from content subjects or academic or scientific disciplines.

This different notion of content which is the most typical feature of the approach is of great interest in the current discussion on improving foreign language competence. First, the approach can be adapted to all levels of language teaching: primary, secondary and 
tertiary, for all curricula include academic content; primary curricula on a very basic level (social sciences, natural sciences, arts), secondary curricula more specifically in content subjects (history, geography, mathematics), and tertiary curricula are characterised by the fact that the content of the students' disciplines (Information Technology, Physics, Engineering, Sociology, Arts, Design) can at least partially be introduced into their language studies. And second, integrated content and language teaching saves time within the overall curriculum. If content and language are learnt and taught in integration and not in isolation the time available for the teaching/learning process of a content subject and a foreign language doubles; length of study time both for language and content subject can thus be reduced considerably, and as a consequence, more languages can be introduced into the curriculum.

Although the practical experience we have with teaching content through a foreign language is, as I said before, very positive, especially in secondary schools where this type of approach is quite common now at least in some European countries, a number of important learning theoretical and pedagogical questions still remain to be answered. We have to ask ourselves, for example, in what way language is learnt in such a classroom despite the fact that teachers do not so much focus on language; we have to ask ourselves as well in what way learners grasp complex academic content although learning takes place in a foreign language. These questions concern psychological aspects of the learning process. And as foreign language teaching specialists we have to ask ourselves how we can optimally organise the learning environment in such classrooms, for at present, despite their great success, they are still organised in a rather traditional way. The first two questions have something to do with a specific way of transfer of language and transfer of content from a teacher to a learner, the last one is rather geared towards creating good conditions for transfer of language and transfer of content.

In the first part of my paper I will propose a definition of the term content and language integrated learning. Then I will sketch out very briefly three approaches to content and language integrated learning, one focussing on primary, one on secondary and one on tertiary education. In the second part I will look at content and language integrated learning from an SLA perspective, focussing on the interactionist approach and what it has to say about learning a foreign language through interaction. I will argue that the interactionist approach can only partly explain the language learning process in such an integrated context. The third and central part of my paper is devoted to cognitive psychology and constructivism as learning theories and as pedagogical approaches. I will try to show that these theoretical concepts are capable of explaining why an integrated language and content approach can promote both language and content learning to such a high degree. The last part of my paper will deal with the third question: I will try to show what a classroom in which learners learn content and language in integration should look like.

\section{Content and language integrated learning in primary, secondary and tertiary education}

Before looking at content and language integrated learning from a learning theoretical and a pedagogical angle, I would like to present this approach in some more detail and relate it to the different levels of the educational process. I will begin with a general definition of the term. 


\subsection{A definition of content and language integrated learning (CLIL)}

7 "Content and language integrated learning" has been introduced recently as a common term for a number of similar approaches in Europe to teach content subjects through a foreign language. Other terms used are "bilingual content teaching", "bilingual subject teaching" or "content-based language teaching". The term CLIL is now the most commonly used, however, especially since a definition has been found which seems to be acceptable to everybody:

Content and language integrated learning (CLIL) is a generic term and refers to any educational situation in which an additional language and therefore not the most widely used language of the environment is used for the teaching and learning of subjects other than the language itself. (Marsh \& Langé 2000: iii)

There are at least three points which are essential in the context of this general definition. The most important one is that CLIL must not simply be regarded as an approach to language teaching and learning but that it is concerned both with content and language. Many scholars tend to believe that within the CLIL paradigm content subjects are taught in a foreign language only to improve the students' foreign language competence. But this is not the intention of this approach, which is geared towards content learning as much as towards language learning. Recent research has made it clear that although foreign language proficiency is improved within CLIL even when the most traditional methodology imaginable is used, the content subject benefits as much from such an approach. From what we know now about content subject learning in a foreign language we understand that learners learn better and are more motivated than those in traditional content subject classrooms. It has also been shown that learners look at content from a different and broader perspective when it is taught in another language. And probably the most interesting research result is that learners develop more precise concepts when another language is involved (cf. Lamsfuss-Schenk, 2002). Some researchers even believe that in CLIL content subject related intercultural learning takes place (Christ 2000). Although the arguments brought together under this first point come from research in secondary education they are also important for tertiary and primary education.

The second point is equally important: within a CLIL framework content and language are learnt in integration. The two subjects - a language and a content subject like history or geography - are related to each other and dealt with as a whole. This does not take place within the traditional school or university framework, where learners have difficulties in establishing relationships between subjects (cf. Hallet 1998), it is a pedagogical principle, however, in primary schools.

The last point in the definition I would like to highlight has something to do with the way language is dealt with in the classroom. In my definition it is stated that other languages are used to teach and learn content subjects, i.e. that they are the medium of instruction. This does not mean, however, that language as such should not be focused upon in the classroom. Language is both content and medium in the CLIL classroom. This distinguishes CLIL from what is usually called immersion in language teaching methodology. On the other hand, in the CLIL classroom language is not taught in the same way as in a traditional classroom - it is focused upon when it is necessary and 
important for the understanding of a specific aspect of the content subject or the academic discipline.

\subsection{CLIL in primary education}

11 The number of primary schools in Europe which have adopted some kind of CLIL approach is surprisingly high. Primary CLIL schools mainly exist in bilingual border regions, in France for example in Alsace, in Italy in Southern Tyrol or in the Aosta Valley. In Germany we find primary CLIL schools also in large industrial centres, for example in Berlin, where primary classes include learners of often up to eight different mother tongues. In France and Italy the minority languages (German and French) are used as the languages of instruction, in Germany one of the larger minority languages is the language in which part of the content is taught. In Berlin this is Turkish, Greek, Spanish or Italian.

The holistic methodological approach which is characteristic of primary education makes it necessary to integrate the foreign language into the subject areas taught in the classroom. The larger subject areas are language (mother tongue and foreign language), natural sciences, social sciences, arts and sports; they are taught partly in the majority language and partly in the minority language chosen. In the 14 primary CLIL schools in Berlin non-German children are chosen according to their first language and put together with an equal number of German speaking children, so that we have Turkish-German, Spanish-German or Greek-German classes. Children have separate language classes, both in the mother-tongue and in the foreign language, and content areas are taught half in German and half in the other language. Native speakers of both languages teach mother tongue and foreign language classes, content is often taught in tandems.

\subsection{CLIL in secondary education}

13 From a survey which was undertaken recently (Marsh, Maljers \& Hartiala 2001) some important information was gathered as to organisational and structural aspects of CLIL in secondary schools in Europe. Although CLIL has developed differently in different European school systems there are a number of similarities which should be mentioned here in order to make the approach more transparent as an educational framework.

In general, CLIL schools or CLIL branches in European schools are designed in such a way that one or more content subjects (in general from the humanities and social sciences) are taught in a foreign language for at least four years. The content subjects most frequently chosen are history, geography and social sciences. The most frequently used languages are English and French, German ranking third. In general, it can be estimated that in CLIL schools the age span of learners reaches from ten to twenty-one years. The number of schools offering preparatory language classes for CLIL is fairly small; if Germany is excluded, where preparatory courses are compulsory, not more than 15 percent of the schools make such an offer.

15 Apart from the German-speaking countries, where teacher education focuses on two subjects, teachers are usually either content subject teachers or language teachers. Content subject teachers are often native speakers of the CLIL language, language teachers in many countries acquire an additional qualification in a content subject.

Materials for content and language integrated learning often come from the countries in which the language used for content teaching is the official language. In general, teachers 
use both authentic and textbook materials (the latter from the content subject textbooks available in these countries). Teachers also adapt authentic or other materials to the linguistic level of their students or write their own materials.

Apart from Germany curricula developed by educational authorities do not exist. In most countries the schools or the CLIL teachers develop their own curriculum. In almost all countries the general principle underlying curriculum development is that learners having learnt content through the foreign language are expected to know as much about the content subject as learners in a mother-tongue course. Often, however, content subject curricula are modified compared to mother-tongue curricula, and especially in history or geography more content related to the culture underlying the language is introduced.

\subsection{CLIL in tertiary education}

It is interesting to note that in tertiary education it is mainly vocational schools which have opted for teaching content through a foreign language. In these schools the content subjects are, in general, different from secondary schools, ranging from information technology to economics. In some of the smaller European countries like in Finland or the Netherlands management or professional schools exist which educate their students entirely in a foreign language, usually English. In colleges and universities, however, CLIL is only rarely used as a methodological approach to language and content teaching. Apart from academic subjects like "English Studies" or teacher training programmes geared at future teachers of English which are at least partly taught in English, the number of academic subjects taught in a foreign language is still comparatively low. Even if languages are part of a university curriculum they are learnt separately and not in integration with the content of the academic subject. This is true even for the initiatives taken by university councils in Germany and similarly in France to offer entire university programmes in English in order to attract foreign students from other, especially Asian countries. These initiatives were not very successful. This has, of course, something to do with a lack of the linguistic competence necessary to teach one's own academic subject in another language. But still, the few examples known show that CLIL is an interesting approach even at tertiary level.

"Why can CLIL be advantageous in tertiary professionally-oriented education and what are the broad educational advantages?" This question is asked by Marsh, Marsland \& Stenberg (2001:17) in their book Integrating Competencies for Working Life and their answer is a list of five key reasons for introducing CLIL in an academic or professional curriculum. According to them these reasons involve the development of

1. Pragmatic knowledge and skills

2. Interpersonal skills

3. Intercultural communication

4. Quality of learning and teaching in the content field

5. Employability.

6. (I would like to add a sixth one: multi-perspectivity, i.e. to be able to look at one's own academic subject from different perspectives).

I cannot go into more detail here with respect to the importance of a CLIL approach in the context of promoting language and content subject competence. Suffice it to say that the 
scant research which has already been done on CLIL has shown that both language and content subject learning benefit enormously from such a methodological set-up. We still don't know yet, however, why this is the case. In the following I will try to discuss some of my own assumptions which are embedded in Second Language Acquisition Research but more in Constructivist Learning Theory and pedagogy.

\section{SLA theory and content and language integrated learning} beginning of my paper: In what way is language learnt in a CLIL classroom although teaching/learning does not focus on language? In order to approach this learning psychological question more closely let us have a look first at what CLIL classrooms look like. Let us describe their typical methodological features, what learners and teachers do in such a classroom.

Of course, methodological approaches to CLIL are varied, ranging from highly traditional teacher-centered to distinctly learner-oriented approaches - the latter still being largely in the minority. But common to all of these classrooms is the constant use of the foreign language in the classroom both in its oral and in its written form, in its receptive as well as in its productive mode. Learners read academic texts, make notes about their content, present the results of their reading processes and listen to the teacher or other learners presenting their results. The foreign language is the medium of instruction, but it also becomes the content of instruction whenever learners have difficulties with it. Although language work is not in the centre of classroom activities learners nevertheless develop a foreign language competence, however, which goes far beyond that of ordinary foreign language learners both at secondary and tertiary level.

To find an explanation for this clearly established fact adherents of CLIL claim that it is exposure time which makes all the difference. In a secondary classroom, they say, learners are exposed to the language six to seven hours a week instead of three to four hours in a normal language classroom: they make use of the foreign language more frequently and thus internalise it more quickly and more deeply. This is, of course, a rather simplistic explanation.

This is where second language acquisition research (SLA) comes in. What are the results of SLA research concerning exposure time? In general, SLA researchers claim that it is not certain at all whether exposure time alone can account for a more highly developed foreign language competence in CLIL learners. Exposure time can only be one factor among others in language learning, and length of exposure alone does not result in high language proficiency. This is documented, for example, by research on migrant workers who have often spent long periods of time in another country without having acquired even a rudimentary knowledge of the other language.

Within SLA a number of different theoretical constructs have been developed which attempt to explain acquisitional processes both of natural and instructed language learners. In my opinion neither the Universal Grammar nor the Monitor Model have enough explanatory power to make us understand why and in what way language learning takes place in a CLIL setting. The only theory which to me seems powerful enough is the so-called interactionist position. As I will show in a moment, however, 
interactionists can only partly explain what takes place in instructed second language learning of the CLIL type.

What does the interactionist position claim? The main idea behind it is that second language acquisition takes place through conversational interaction. Researchers like Hatch (1992), Long (1983) and Pica (1994) argue that what Krashen (1982) calls comprehensible input is necessary for language learning, but that in order to understand the effect interaction has on the learning process the question must be answered how input is made comprehensible. Interactionists claim that this takes place through negotiation of meaning. Interaction involves negotiation of meaning and this entails modification of input which in turn makes input comprehensible. So actually what promotes acquisition is interactional modification. Later on, in the development of the theory, a more far-reaching argument was added. Through modification, it was claimed, the learner's attention is focussed on a specific linguistic structure of the target language which is thus taken in and learned.

There can be no doubt, that the interactionist position is a very interesting candidate with respect to an explanation of language learning within a CLIL setting. Input, comprehension and interaction are the driving forces behind this explanation, and (academic) input, receptive and productive processing of content and interaction are the key features of the CLIL classroom.

But although the interactionist position as such presents a powerful theoretical claim it is yet limited in several respects:

1. Conversational interaction has been analysed only in contexts involving native speakers and non-native speakers. The native speaker is, in general, the interlocutor who brings about the interactional modification necessary, and there is only very little research being done on modification in non-native speaker interaction.

2. Research data come almost exclusively from contexts in which the target language of the learner is also the majority language of the country. Thus, the interactionist position is based on natural and not so much on instructed acquisitional data.

3. Only interaction of a conversational type has been analysed in this research. Other more formal types of interaction, for example academic discussions, or transactional interaction, have not been investigated at all.

4. Input as such is not being discussed as a relevant factor in the acquisitional process. At least in the early stages of the interactionist theory the type of the content of the interaction does not play a role: whether a conversation is about everyday or academic matters does not seem to be of any interest in the explanation of the acquisitional process.

5. The interactionist position like all the other theoretical aproaches to SLA up to now lacks a detailed consideration of the term "comprehension" which is probably the solution to the whole problem. What does it mean to comprehend an utterance, an interactional turn? Comprehension is only looked at from a linguistic perspective as something which can be deciphered by means of one's linguistic knowledge. As I will show in a moment, comprehension involves other factors which can be helpful in understanding acquisition.

When looking at the interactionist position in SLA now (cf. for example Platt \& Brooks 2002), it becomes clear that some of the earlier weaknesses of the approach have been recognised and are about to be mended. In Platt \& Brooks' paper it is argued that task engagement plays an important role in the language learning process. They assume that language learning takes place while learners interact in the target language when engaging in a task which they have to solve. The tasks which they use for data elicitation 
are jigsaw tasks in which informants have to complete pictures or maps by interviewing their partners who possess this information. Interaction is seen here as a social process during which meaning is constructed jointly by both partners.

It is interesting to note when looking at this research that there is a shift in focus: for the first time researchers are looking at the content of the interaction (it is still conversational interaction, but content is a controlled variable) and for the first time they come up with a non-linguistic argument in order to explain the language learning process - namely social construction of meaning. Both aspects are important for my own argumentation in the next part of my paper.

31 Let me sum up my position with respect to SLA research. Even the most plausible approach to SLA theory, the interactionist position, is not able to fully explain why learners in a CLIL classroom learn language, and especially why they learn language better than in an ordinary classroom. Although the interactionist position comes forward with a number of proposals which can be of interest as part of an overall CLIL learning theory - I am thinking here especially of the concepts of input, comprehension and interaction - I believe that it cannot explain the content and language learning process as such. It does not convincingly explain why language learning takes place, and it does not take up the question of content learning at all. The key to an understanding of language learning within a CLIL setting seems to me to lie in the kind of input, in the nature of the comprehension process and in the way interaction takes place. To make this claim more transparent we have to look at another discipline, constructivism and constructivist psychology.

\section{Constructivism and content and language integrated learning}

Constructivism as a theory of knowledge and of knowledge development is important in our context because it provides an explanation both for human comprehension and for human learning, which are key issues with respect to the questions posed to content and language learning in a CLIL context.

\subsection{Some important concepts of constructivism}

It is understandable that I cannot deal with constructivism in any detail here: I will just pick out some issues which are related to the key features of CLIL and thus important for my arguments. The issues dealt with are human comprehension, interaction, input and learning.

In constructivism several theories of human comprehension have been developed which are all based on the assumption that comprehension is a constructive process. Cognitive psychology as one branch of constructivism regards comprehension as a cognitive process in which knowledge available in the human mind interacts with the outer stimuli perceived by the comprehender. The result of this interaction process is an individual construct which the comprehender will store in his memory provided he judges it important enough. Schools of cognitive psychology differ according to the importance they ascribe to the incoming stimuli and to the available knowledge in the construction process. This general theory of comprehension is true for all epistemological processes, it 
must be extended, however, with respect to language comprehension. It can be assumed that the knowledge store of the comprehender is subdivided into two components, a world kowledge and a language component which interact in order to make sense of the incoming stimuli. The perceptual stimuli which enter the processing space in a sensory mode (sound waves, letters) have to be transformed into something cognitive.

In social constructivism, the locus of the process of construction and of comprehension is shifted from the inside, i.e. the comprehender's mind, to the outside, the social world in which interactiontakes place. Based on Bakhtin's ideas (cf. Bakhtin 1981) social constructivists claim that participants in an interaction jointly construct meaning during the interactional process. Clearly, the individual knowledge of the participants (personal constructs), both their experience of the world and their linguistic knowledge, play an important role in this process; it is equally important, however that the individual knowledge stores are coordinated by the participants during the interaction. Clark (1996) has developed a model of face-to-face interaction in which he defines conversational interaction as "joint action built on individual actions" and argues that speaking and listening are not independent of each other: "Rather they are participatory actions, like the parts of a duet, and the language use they create is a joint action, like the duet itself".

Thus, social constructivists can convincingly explain comprehension processes as being embedded in interactional contexts; cognitive psychologists have developed a framework for explaining individual comprehension processes: only both approaches taken together can explain comprehension as such.

All constructivist comprehension theories underline the importance of inputin the construction process. It is not the input as such which is important for successful processing, however, but rather the significance it has for the comprehender. Like Comenius cognitive psychologists argue that a comprehender can only process input successfully if he can relate it to knowledge which is already part of his knowledge store. Social constructivists carry their argument even further; according to them only input in which the comprehender can get engaged or even involved in, can be processed and will, in the end, lead to a construction which he can make use of. So in constructivist theory it is not, like in SLA, simply meaningful input which is of importance for language processing, but input which is meaningful, but also significant and involving for the comprehender.

All constructivists whether radical or more moderate emphasise that human cognition and human learning are constructive operations which the learner organises and carries out autonomously. Learners can only comprehend and learn items which they can assimilate with knowledge already available. They also underline that the results of learning processes are different for each learner, because learners during their construction processes makes use of their individual subjective knowledge. Constructivists also try to integrate human emotion into their concept of construction. Emotions are constructions and influence the cognitive processes and thus the construction of the world. One last point is that constructivists emphasise the importance of the social context within which learning takes place. Learning is always socially mediated and necessitates a social context, i.e. partners who co-operate in the learning process. 


\subsection{Constructivism and CLIL classrooms}

39 I mentioned above that interactionists attribute a certain degree of importance to comprehension in their theory: they maintain that input has to be comprehensible and they tacitly assume that comprehension is necessary in order to learn language. But they do not take into account the psychological concept of comprehension in their attempts to explain language learning. As I just said, constructivists tell us that comprehension is a constructive process which necessitates a high amount of complex mental activities: comprehension is not a reactive and purely receptive process as proponents of earlier models of communication have made us believe. Listeners and readers do not simply receive outside stimuli, they do not just transform these stimuli into something which they can store in their memory. While doing this they have to activate their world and language knowledge stores, they have to infer meanings, they have to elaborate on what their interlocutor says. Comprehension is a highly active constructive process, and it is here that the key to language learning lies. It is not wrong to say that language learning takes place whenever a learner engages in a constructive comprehension process. Language learning does not take place when the learner does not activate his constructive abilities but just takes in receptively the stimuli which his perceptual system discerns. As we all know, this is often the case in instructed language learning in school or university, where learners believe that in monotonously working through formal exercises they will learn language.

The so-called levels-of-processing theory provides an additional argument for my assumption. Already in 1972 Craik \& Lockhart developed a model of human memory which is characterised by three important points: (1) Depth of processing of an item is an important concept with respect to retaining this item in memory. (2) Depth of processing has nothing to do with the frequency of rehearsing the item, it rather depends on the meaning which the comprehender extracts from the item. (3) Deeper processing leads to more complex, more permanent and more powerful memory traces. From another perspective the levels-of-processing theory emphasizes the importance of looking at comprehension as an active and constructive process.

41 It is thus the active manipulation of language integrated in content during the construction process which makes language learning possible. Language is learnt when, during the comprehension process, learners are trying to make sense of what they read or listen to. Language is learnt because meaning is constructed. This assumption holds true both for first and second language learning.

Focussing on comprehension as the key component of the language learning process does not yet explain, however, why second language learning in a CLIL context is so much more efficient than in an ordinary classroom. It is here that input or content comes in. In traditional language classrooms all learning content is pre-defined, simplified and graded. It is reduced to fairly stereotypical sequences of everyday life. Most of the materials used are not authentic but designed by textbook writers to fit a communicative and/or linguistic progression. The integration of content subjects makes an enormous change here. Geography or history provide rich learning content for the classroom content which is real and not fictitious and thus is more motivating than that usually dealt with in language classrooms. The learning contents of most content subjects are, what could be called "realia", i.e. facts and processes of the real world, and thus appear 
much more relevant than the often pseudo-real contents of the language classroom. They are characterised by a scientific orientation and are, therefore, richer and more complex than most content dealt with in ordinary language classrooms.

The focus on input relevant for the learner in the CLIL classroom provides an answer to both of my first two questions. The content the CLIL classroom provides for the learner is more significant than the content of the traditional classroom, it is more motivating and more involving, and they process it more attentively. For the learners in primary and secondary schools, who are more interested in the world around them than in the fictitious characters appearing in their text books comprehension processes become more active; deep instead of shallow processing takes place. Thus, content and language learning become more intensive and more successful than in ordinary classrooms. Similarly, at tertiary level the content of the language course, when related to the academic subject studied, is more significant to the student than the everyday content of the typical course textbook.

It is significance, motivation and involvement which are the driving forces activating comprehension and thus making language and content learning more efficient. They are triggered off by the more academic learning content. Learners learn language and content in the CLIL classroom more successfully because they are more involved in content.

It is hardly necessary to underline that interaction also plays an important role in an explanation of language learning based on constructivist principles. But the role of interaction is different from what the interactionist theory of SLA proposes. Whereas in SLA research negotiation of meaning and modification of input are concepts which are entirely related to language - input is modified with respect to language and not to content - the role of interaction in a constructivist approach extends both to content and to language. From a constructivist perspective the main aim of an interaction is not negotiation of language and thus language learning but rather negotiation and construction of content and thus also transfer of content. Language learning is seen as a by-product, it takes place because content (not input) is socially constructed. Like comprehension interaction provides the ground for construction and thus opens the way for learning. It is clear that an environment which is suited for social interaction will better promote learning and language learning processes. This leads me to my last point, the organisation of a learning environment in which the potential of CLIL can be used to its full extent.

\section{The potential of CLIL in the classroom}

In a traditional learning environment the learning context is dominated by decisions made outside the classroom: by the administration or by the school. In innovative CLIL classrooms the learning environment is created in co-operation between students and teachers. Together they set up a kind of learning laboratory in which they experiment and do research and thus deal with their learning content in a motivating way. Experimentation and research is more realistic, more motivating and more involving for the students because they deal with concrete topics from the field of geography or history and work, let us say, with temperature charts or historical maps. Research and experimentation can also be carried out with language, of course, but a learning laboratory lends itself much more readily to investigation in social and natural sciences. 
The content subject makes research and experimentation more realistic than a language. In a way, experimentation with language can be prepared through more realistic research in the content subject. It is hardly necessary to mention that research and experimentation are highly motivating and involving activities.

In such a classroom the only accepted social form of learning should be group work. In an innovative classroom, which is regarded as a research laboratory, occasions for group work are much more numerous. It is clear that content subjects, with their rich potential for research and experimentation, add a new dimension to group work. They add authenticity to it; one could even go so far as to say that content subjects enforce group work in the classroom. In this way a framework for social interaction is provided which contributes, as I pointed out above, both to learning and to language learning.

The last point I would like to mention here is learning strategies. I suggest that learning strategies have a very high potential with respect to the promotion of learning and language learning. Only learners who have learned to work with specific learning techniques and study skills will be successful learners. Learning techniques and study skills are very complex abilities in language learning. But they are also highly important in the content subject classroom. Focussing on learning strategies in a CLIL environment will help to promote students' strategic abilities both in language and content learning.

\section{Final remarks}

There can be no doubt that CLIL is a very important new paradigm in language teaching which is worthwhile to try out even in tertiary environments. The target language need not always be English, other languages like German or a Romance language can be promoted in this way as well. The more languages our students know in their professional field the better they will be qualified for their profession. English is not a foreign language any more, it has become a key qualification for everyone. A professional qualification starts with a third or fourth language, and CLIL shows a way in this direction.

\section{BIBLIOGRAPHY}

Bakhtin, M. 1981. The Dialogic Imagination: Four essays. Austin, TX: University of Texas Press.

Christ, H. 2000. „Zweimal hinschauen - Geschichte bilingual lernen“. In Bredella, L. \& F.J. Meißner (eds.). Wie ist Fremdverstehen lehr- und lernbar? Tübingen: Gunter Narr, 43-83.

Clark, H. H. 1996. Using Language. Cambridge: Cambridge University Press.

Craik, F.I.M. \& R.S. Lockhart. 1972. "Levels of processing: A framework for memory research". Journal of Verbal Learning and Verbal Behavior 11, 6671-684.

Hallet, W. 1998. “The bilingual triangle: Überlegungen zu einer Didaktik des bilingualen Sachfachunterrichts". Praxis des Neusprachlichen Unterrichts 45, 115-125. 
Hatch, E. 1992. Discourse and Language Education. Cambridge: Cambridge University Press.

Krashen, S. 1982. Principles and Practice in Second Language Acquisition. Oxford: Pergamon

Lamsfuß-Schenk. 2002. „Geschichte und Sprache - Ist der bilinguale Geschichtsunterricht der Königsweg zum Geschichtsbewusstsein?". In Breidbach, S., G. Bach \& D. Wolff (eds.). Bilingualer Sachfachunterricht: Didaktik, Lehrer-/Lernerforschung und Bildungspolitik zwischen Theorie und Empirie. Frankfurt: Lang, 191-206.

Long, M. H. 1983. "Native/non-native speaker conversation and the negotiation of comprehensible input”. Applied Linguistics 4, 126-41.

Marsch, D. \& G. Langé (eds.). 2000. Using Languages to Learn and Learning to Use Languages. Jyväskylä: University of Jyväskylä.

Marsch, D., A. Maljers \& A.-K. Hartiala (eds.). 2001. Profiling European CLIL Classrooms:Languages Open Doors. Jyväskylä: University of Jyväskylä.

Marsch, D., B. Marsland \& K. Stenberg. 2001. Integrating Competencies for Working Life. Jyväskylä: University of Jyväskylä.

Pica, T. 1994. "Research on negotiation: What does it reveal about second language acquisition? Conditions, processes, and outcomes". Language Learning 44, 493-527.

Platt, E. \& F.B. Brooks. 2002. “Task engagement: A turning point in foreign language development”. Language Learning 52, 365-400.

\section{ABSTRACTS}

This paper looks at transfer from a pedagogical and a learning psychological perspective. The question is raised whether an integrated approach to language and content in the language classroom will help to promote both language and content learning and can be regarded as more efficient than an isolated approach to language. This question does not seem to be very original at first sight: people like Harold Palmer in the beginning of last century already argued that languages cannot be taught and learned without being embedded in content. But the question takes on a different quality if content is defined as something more complex than what is usually introduced into the traditional language classroom. Content for the language classroom is traditionally taken either from everyday life (like in school textbooks) or from specific aspects of the culture of the target language (usually in university language courses). Content can, however, also be of a more academic and scientific nature. In school content can be represented by a socalled content subject like Geography or History which could be taught entirely or partly in the target language; at university the academic subjects studied by the students can also at least partly be taught in a foreign language. Such a proposal is not entirely new: in a number of schools in Europe content and language integrated learning has been introduced as a way of promoting multilingualism, and in a few universities at least some modules of certain academic subjects - like economics or information technology - are taught in a foreign language. The issue I would like to deal with in this paper concerns the feasibility and efficiency of such an approach. There can be no doubt that integrating content and language saves time. Learners are exposed to content and language at the same time: they learn language while they learn content, and they learn content while they learn language. This is why exposure time can be higher for both learning components (language and content) than it could be if they were taught in isolation. But the question arises what effects this has on the acquisition of content? The question also arises, of course, in what way a specific academic or scientific kind of content influences the language 
learning process. And finally it is highly important to look at the question in what way the learning environment changes if academic content and language are brought together. In my paper I will try to answer these questions and, at the same time, argue that content and language integrated learning as a pedagogical approach has the potential to modify language and content teaching both in school and at university.

Cet article s'intéresse à la question du transfert dans une perspective pédagogique et psychologique. Il pose la question de savoir si une approche intégrée de la langue par le contenu (CLIL = Content and language integrated learning) est plus efficace qu'une approche plus sélective de la langue pour promouvoir à la fois les langues et les contenus abordés. Le contenu doit être compris non seulement comme pouvant faire référence à un contexte quotidien ou même culturel spécifique mais aussi comme pouvant viser, à un niveau élevé, certains sujets enseignés au cours des études, depuis le cycle primaire jusqu'à l'enseignement supérieur ou dans un cadre professionnel. Il s'agit donc de savoir si cette approche, qui n'est pas nouvelle (cf. les travaux d'Harold Palmer au début du siècle dernier et ce qui existe déjà dans de nombreuses écoles en Europe), est réalisable et efficace en termes d'économie de temps, en termes d'acquisition de la langue cible et des contenus, et si elle a des répercussions sur la nature même des contenus abordés et des pratiques linguistiques choisies.

\section{INDEX}

Keywords: CLIL, constructivism, interactionism, second language acquisition

Mots-clés: acquisition des langues, constructivisme, content and language integrated learning

\section{AUTHOR}

\section{DIETER WOLFF}

Dieter Wolff est titulaire de la chaire de Psycholinguistique Appliquée à l'université de Wuppertal (Allemagne). Sa bibliographie compte environ 200 publications sur la linguistique appliquée (didactique), la psycholinguistique, l'éducation bilingue et l'usage des TIC dans l'enseignement et l'apprentissage des langues. Il est rédacteur en chef et membre du bureau éditorial de plusieurs revues portant sur l'enseignement et l'apprentissage des langues. Il est également vice-président de AILA, ex-président de GAAL (l'association allemande de linguistique appliquée) et consultant pour plusieurs agences nationales et internationales en charge d'harmoniser les politiques d'enseignement des langues. wolff.dieter@t-online.de 